\title{
DEFERVESCENCE PERIOD OF AZITHROMYCIN VERSUS CEFTRIAXONE IN CHILDREN WITH ENTERIC FEVER
}

\author{
Aziz Langah ${ }^{1,2}$, Muhammad Nadeem Chohan ${ }^{1,3 凶}$, Abdul Hameed Radhan ${ }^{1,3}$, \\ Muhammad Asif ${ }^{1,4}$
}

\begin{abstract}
OBJECTIVE: To compare the defervescence period of azithromycin versus ceftriaxone in children with enteric fever.

METHODS: This open-label, randomized-controlled trial was conducted at Pediatrics Department, Federal Government Polyclinic Hospital, Islamabad, Pakistan from June 30, 2015 to December 30, 20I5. Sample size calculated was 99 by using WHO sample size calculator. Patients of either gender, aging 2- 12 years, diagnosed as enteric fever were eligible for study. One hundred eligible patients selected through non-probability consecutive sampling technique were recruited in the study, after seeking an informed consent from the parents. These patients were randomized through lottery method in two groups of equal size $(n=50$ each). Group A, received oral azithromycin suspension/capsule $(10 \mathrm{mg} / \mathrm{kg} / \mathrm{day}$; maximum dose, $500 \mathrm{mg} /$ day) administered once daily for 7 days, while Group B received intravenous $(\mathrm{I} / \mathrm{V})$ ceftriaxone $(75 \mathrm{mg} / \mathrm{kg} /$ day; maximum dose, $2.5 \mathrm{~g} /$ day) administered twice daily for 10 days. The clinical response to the therapy of both drugs was calculated in terms of number of days taken for defervescence. Data was analyzed in SPSS version 22.0.
\end{abstract}

RESULTS: Out of 100 patients, 64 (64\%) were males and 36 (36\%) were females and mean age of patients was $7.08 \pm 3.013$ years. Patients on azithromycin had the mean time of defervescence $4.08 \pm 0.922$ days and patients on ceftriaxone, the mean time of defervescence was $4.06 \pm 1.038(p=0.919)$.

CONCLUSION: There is no significant difference between oral azithromycin and intravenous ceftriaxone in term of defervescence period for the treatment of enteric fever in children. Azithromycin could be a suitable alternative owing to its convenient dosing and monitored on outpatient basis.

KEY WORDS: Defervescence (Non-MeSH); Azithromycin (MeSH); Ceftriaxone (MeSH); Administration, Oral (MeSH); Injections, Intravenous (MeSH).

THIS ARTICLE MAY BE CITED AS: Langah A, Chohan MN, Radhan AH, Asif $M$. Defervescence period of azithromycin versus ceftriaxone in children with enteric fever. Khyber Med Univ J 2020;12(3):192-6. DOI: 10.35845/kmuj.2020.19085.

\section{INTRODUCTION}

$\mathrm{T}$ yphoid fever is caused by Salmonella typhi and Paratyphi. Usually it is a mild condition but it can be fatal among children in developing countries. About 21 million cases and 200,000 deaths occur annually due to enteric fever, with an incidence of 100 to I,000 cases/ I 00,000 population.'

In past chloramphenicol was used for the treatment of enteric fever but nowadays S. typhi is resistant to it. ${ }^{2}$ Currently quinolones have proven to be effective; but $\mathrm{S}$. typhi resistant strains are also reported. ${ }^{3}$ Cephalosporins, especially ceftriaxone is very effective against S. typhi ${ }^{4}$ as ceftriaxone is given parenterally, that's why it is less than ideal treatment alternative. Most recently azithromycin (macrolide) has a good option for the treatment of typhoid fever. ${ }^{5}$ Clinical response of azithromycin was studied in one study where mean defervescence of time
I. Department of Paediatrics, Federal Government Polyclinic (PGMI), Islamabad, Pakistan.

2. Department of Paediatrics, Peoples Women Medical University, Shaheed Benazir Abad, Pakistan.

3. Department of Paediatrics, Liaqat University of Medical and Health Science, Jamshoro, Pakistan.

4. Department of Paediatric Cardiology, National Institute of Cardiovascular Disease, Karachi, Pakistan Email $^{\mathbb{1}}$ : nadeem.chohan@lumhs.edu.pk Contact \#: +92-334-039786 I

$\begin{array}{ll}\text { Date Submitted: } & \text { March 03, 2019 } \\ \text { Date Revised: } & \text { May 04, 2020 } \\ \text { Date Accepted: } & \text { May 08, 2020 }\end{array}$

(days) was $4.1 \pm \mathrm{I} . \mathrm{l}$ and $3.3 \pm \mathrm{I} .2$ for ceftriaxone. $^{6.7}$

Studies have shown a reduced clinical failure rate and relapse rate by azithromycin as compared to fluoroquinolones and ceftriaxone, when treating typhoid fever. ${ }^{8}$ Cost, compliance, safety and efficacy, should be considered in countries like Pakistan, which has limited resources.

From 2018 onwards, increased cases of multi-resistant enteric infections in children are admitted from various areas of Karachi at Abbasi Shaheed Hospital (ASH). Only 3.64\% children showed sensitivity to ceftriaxone while $32.8 \%$ were sensitive to azithromycin. As azithromycin is orally available and unlikely ceftriaxone, it can be used for patients in outdoor department without need of hospitalization, a study was needed to compare both these drugs in enteric fever in our pediatric population. This study was planned to compare the efficacy of azithromycin with ceftriaxone in children with enteric fever in term of the defervescence period. 


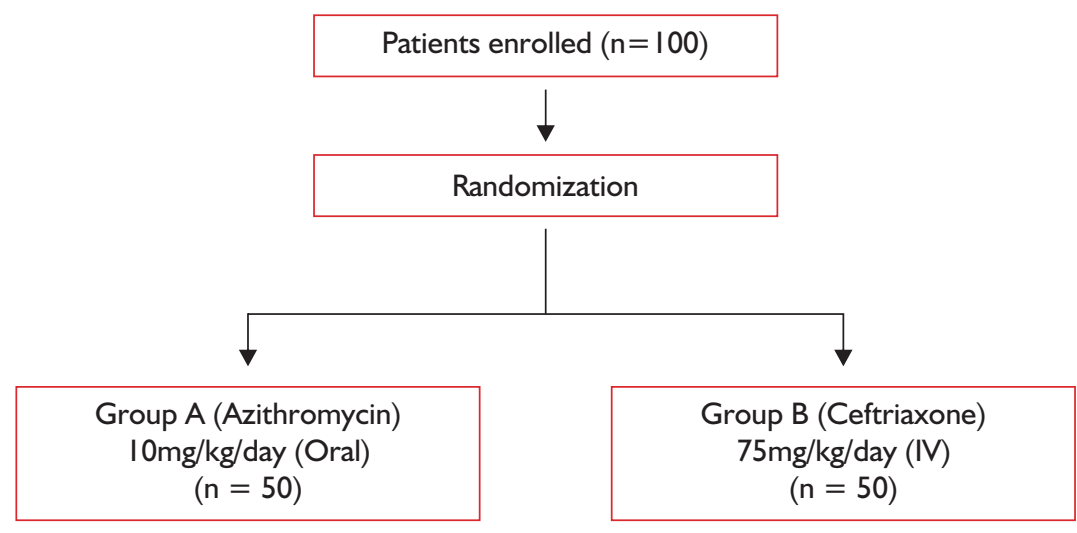

Figure I: Flow chart of participant screening

\section{METHODS}

This open label, randomized controlled trial (RCT) was conducted at Department of Paediatrics, Federal Government Polyclinic (PGMI), Islamabad from June 30, 2015 till December 30, 2015. Approval was taken from College of Physicians and Surgeons Pakistan before starting the study (REU NO: 7273) and ethical approval was granted by Research Ethics Committee of Federal Government Polyclinic Post Graduate Medical Institute, Islamabad.

Sample size was calculated by using WHO sample size calculator with significance of $5 \%$, power of test $80 \%$, pooled standard deviation I.I5 days, population test value of mean 4.1 days (azithromycin) Population mean 3.34 days (ceftriaxone). ${ }^{10}$ Sample Size calculated was 99, approximately 50 patients in each group.

Inclusion criteria set was patients of either sex, diagnosed as fever enteric fever and ranging in age between 2-12 years. Exclusion criteria was allergic to ceftriaxone or azithromycin or enteric fever with pneumonia (CXR), intestinal hemorrhage (stool occult blood) or perforation (erect abdomen X-ray), shock, encephalopathy or dysphagia. Patients with heart disease, chronic asthma or immune-deficiencies (diagnosed on history) were also excluded. In addition, children, who were treated within last 48 hours with antibiotics, also were in the exclusion list.
Eligible patients selected through nonprobability consecutive sampling technique, were enrolled in trial after seeking an informed consent from the parents.

One hundred eligible patients selected through non-probability consecutive sampling technique were recruited in the study, after seeking an informed consent from the parents. These patients were randomized through lottery method in two groups of equal size ( $n=50$ each).

All patients in Group A were treated with oral azithromycin suspension/ capsule $(10 \mathrm{mg} / \mathrm{kg} /$ day; maximum dose, $500 \mathrm{mg} /$ day) once daily for total 7 days

TABLE I: BASELINE STATISTICS OF THE STUDY PARTICIPANTS $(n=100)$

\begin{tabular}{|c|c|c|c|c|}
\hline \multicolumn{2}{|c|}{ Characteristics } & $\begin{array}{l}\text { Azithromycin Group } \\
(n=50)\end{array}$ & $\begin{array}{c}\text { Ceftriaxone Group } \\
(n=50)\end{array}$ & p-value \\
\hline \multicolumn{2}{|l|}{ Age (years) } & $7.14 \pm 3.02$ & $7.31 \pm 2.07$ & $>0.05^{*}$ \\
\hline \multirow{2}{*}{$\begin{array}{l}\text { Age Groups } \\
\text { (years) }\end{array}$} & $3-5(n=22)$ & $13(26 \%)$ & $9(18 \%)$ & \multirow{2}{*}{$>0.05^{*} *$} \\
\hline & $6-10(n=78)$ & 37 (74\%) & $4 \mathrm{I}(82 \%)$ & \\
\hline \multirow{2}{*}{ Gender } & Male $(n=64)$ & $31(62 \%)$ & $33(66 \%)$ & \multirow{2}{*}{$>0.05 * *$} \\
\hline & Female $(n=36)$ & $19(38 \%)$ & $17(34 \%)$ & \\
\hline
\end{tabular}

*Independent samples t-test ** Chi Square test

\section{TABLE II: COMPARISON FOR TIME OF DEFERVESCENCE AND BLOOD CULTURE CHARACTERISTICS IN BOTH GROUPS}

\begin{tabular}{|c|c|c|c|c|}
\hline \multicolumn{2}{|c|}{ Variables } & $\begin{array}{c}\text { Group A } \\
\text { Azithromycin } \\
(n=50)\end{array}$ & $\begin{array}{c}\text { Group B } \\
\text { Ceftriaxone } \\
(n=50)\end{array}$ & p-value \\
\hline \multicolumn{2}{|c|}{ Mean time of defervescence (days) } & $4.08 \pm 0.922$ & $4.06 \pm 1.038$ & $>0.05^{*}$ \\
\hline \multirow{2}{*}{$\begin{array}{l}\text { Blood Culture } \\
\text { for S. Typhi }\end{array}$} & Positive $(n=40)$ & $23(46 \%)$ & $17(34 \%)$ & \multirow{2}{*}{$>0.05^{* * *}$} \\
\hline & Negative $(n=60)$ & $27(54 \%)$ & $33(66 \%)$ & \\
\hline
\end{tabular}


deviation were calculated for quantitative variables like age, time of defervescence (days). Independent samples t-test was used to compare time of defervescence (days) in both the groups. $P$ value $<0.05$ was considered significant. Chi Square test was used to compare the positive blood culture for S. Typhi in both groups

\section{RESULTS}

In sample of 100 patients, the mean age of the participants was $7.08 \pm 3.013$ years, with an age range of $3-10$ years. Twenty-two patients were aging from 35 years and 78 patients were in the age range of $6-10$ years. Amongst the participants, 64 (64\%) were males and $36(36 \%)$ were females (Table I).

In group $A$, the mean time of defervescence was 4.08 \pm 0.922, in group $B$, the mean time of defervescence was noted to be $4.06 \pm 1.038$ (Table II). Independent Sample t-test was used to look for statistically significant difference in mean time of defervescence in the two treatment groups (azithromycin vs. ceftriaxone). The test revealed $\mathrm{p}$-value (2-tailed significance) of 0.919 . In addition, Table Il also revealed the blood culture status in both groups of the participants.

\section{DISCUSSION}

Enteric fever affects about $80 \%$ of cases in Asia among whole world. The incidence of Typhoid fever in Pakistan is 4I3/100,000 people/year.' One of the major problem in treating typhoid fever is emergence of drug resistant strains. ${ }^{2}$ Strains that were resistant to chloramphenicol, co-trimoxazole and ampicillin, initially was reported from Pakistan and India but then spread over globally. Due to this reason, fluoroquinolones became a better choice, but with passage of time, reduced susceptibility to fluoroquinolone were reported. ${ }^{2}$

Ceftriaxone become the treatment of choice for treating typhoid fever, but it is available in injection form. Azithromycin has another option for the treatment of enteric fever. Neutrophil concentrations of azithromycin are
$>100$ times the serum concentration of the antibiotic."

These encouraging results motivated authors to conduct the current study. The present study was done to compare the clinical efficacy of azithromycin vs. ceftriaxone in terms of days for defervescence in typhoid fever. It was hypothesized that azithromycin was more efficacious compared with ceftriaxone while treating Typhoid fever.

The study results showed that mean time (number of days) of defervescence for azithromycin was $4.08 \pm 0.922$, and for ceftriaxone, it was 4.06 1 1.038; the independent sample t-test revealed that this difference was not statistically significant $(p=0.919$ i.e. $>0.05)$. Therefore, we accept the null hypothesis, in that there is no difference in efficacy of both drugs for treatment of enteric fever in children. This is an interesting finding, and indeed quite different from the findings reported in the literature, which favor and recommend either of the drugs due to better efficacy.

A similar study was carried out in India, mean day of response was $3.45 \pm 1.97$, which is almost different from this study finding i.e. mean defervescence time with azithromycin was $4.08 \pm 0.922$ days. ${ }^{2}$ Another similar study from Cairo, Egypt revealed that ceftriaxone had a slightly shorter time to defervescence as compared to azithromycin (3.9 vs. 4.1 days, respectively) and had a insignificant difference. ${ }^{6}$ Few other studies reported results in similarity to our study (i.e., mean time (number of days) of defervescence for azithromycin was $4.08 \pm 0.922$, and for ceftriaxone, it was $4.06 \pm 1.038$; the Independent sample ttest revealed that this difference was not statistically significant $(p=0.919$ i.e. $>0.05){ }^{13-14}$ In another similar study fever clearance time with azithromycin was from 2-5 days with mean fever clearance time $(3.65+0.91$ days $) .{ }^{15} \mathrm{~A}$ study also reported mean time to defervescence using ceftriaxone as 3.9 days. $^{16}$ In similar way, a study in India showed that mean day of response of azithromycin as 3.5 days. ${ }^{17}$ In yet another study from Kashmir, ceftriaxone defervescence period was 4 days in enteric fever. ${ }^{18}$

Ceftriaxone is still used to treat typhoid fever. However resistant to ceftriaxone from Bangladesh and from India is alarming. This emerging resistance in ceftriaxone needs to have an alternate therapy. ${ }^{15-19}$ Recent studies have reported good activity of azithromycin against salmonella typhi. ${ }^{6,20}$ Azithromycin is emerging as a promising agent against Salmonella typhi, because it is effective, defervescence period is shorter, gastrointestinal carriage is eradicated, oral form is available and can be safely used in children. ${ }^{2}$ A study by Qaiser $S$, et al, showed that minimum inhibitory concentration (MIC) of azithromycin was $8 \mu \mathrm{g} / \mathrm{ml}^{2}$ Other studies have reported MICs of azithromycin between $4-16 \mu \mathrm{g} / \mathrm{ml}^{20}$ Azithromycin MIC of $8 \mu \mathrm{g} / \mathrm{ml}$ is also effective because of its high intracellular concentration, at this level it does not cause any relapse or major side effect. ${ }^{6}$ MIC values for azithromycin against Salmonella is different in India as compared to Western countries. Recent studies conducted in India showed MIC for azithromycin was 24 $\mu \mathrm{g} / \mathrm{mL}$; while in the Western countries has values as low as 4 or $8 \mu \mathrm{g} / \mathrm{mL}^{21-25}$

\section{LIMITATIONS OF STUDY}

With relatively small sample size, the results could not be generalized to a larger population. Blinding was not done due to variation in route of administration. Culture for Salmonella was not positive in all cases and enteric fever in these cases was diagnosed on basis of strong clinical suspicion and other tests like Widal \& Typhidot. The relapse rates with both drugs should have been compared and tolerability in terms of adverse events should been also observed for both drugs, to make it a methodologically robust study.

\section{CONCLUSION}

There is no significant difference between oral azithromycin and intravenous ceftriaxone in term of defervescence period for the treatment of enteric fever in children. However, oral azithromycin is to be preferred because of its convenient dosing, which 
can be easily monitored on outpatient basis, especially in developing countries like Pakistan. Intravenous ceftriaxone obviously requires that the patients must be admitted and that puts an added cost on the management of such children.

\section{REFERENCES}

I. Kliegman RM. Nelson Text Book of Pediatrics. $19^{\text {th }}$ ed. New Delhi: Saunders; 20II.954-8.

2. Qaiser S, Irfan S, Khan E, Ahsan T, Zafar A. In vitro susceptibility of Typhoidal Salmonellae against newer antimicrobial agents: a search for alternate treatment options. J Pak Med Assoc 20II;6I(5):462-5.

3. Patel K, Goldman JL. Safety concerns surrounding quinolone use in children. J Clin Pharmacol 2016 Sep I;56(9):1060-75. DOI: 10.1002/jcph.715.

4. Zmora N, Shrestha S, Neuberger A, Paran Y, Tamrakar R, Shrestha A, et al. Open label comparative trial of mono versus dual antibiotic therapy for typhoid fever in adults. PLoS Negl Trop Dis 2018; I2(4): e0006380. DOI: 10.1371/journal. pntd.0006380.

5. Nagaraj P, Sivathanu S, Manickam K, Kumar S, Kumar S, Sampath S. To study the effectiveness of oral azithromycin as compared to parenteral ceftriaxone in the treatment of uncomplicated enteric fever. J Pediatr Infect Dis 2016; II:II3-7. DOI: 10.1055/s-00361593889

6. Vishwanath, Rohit S. Azithromycin versus ceftriaxone--which is better in uncomplicated typhoid fever? A clinical trial in a tertiary care hospital. J Evol Med Dent Sci 2019; 8(17): 1394.

7. Khatun $\mathrm{H}$, Islam $\mathrm{SB}$, Naila NN, Islam SA, Nahar B, Alam NH, et al. Clinical profile, antibiotic susceptibility pattern of bacterial isolates and factors associated with complications in culture-proven typhoid patients admitted to an urban hospital in Bangladesh. Trop Med Int Health 2018 Apr;23(4):
359-66. DOI: $10.11 \mathrm{II} / \mathrm{tmi} .130372$ 018.

8. Veeraraghavan B, Pragasam AK, Bakthavatchalam YD, Ralph R. Typhoid fever: issues in laboratory detection, treatment options \& concerns in management in developing countries. Future Sci OA 2018 Jun 26;4(6):FSO3I2. DOI: $10.4155 /$ fsoa-20|8-0003.

9. Aziz S, Malik L. Emergence of multiresistant enteric infection in a paediatric unit of Karachi, Pakistan. J Pak Med Assoc 2018;68(I2): 184850.

10. Ayub U, Khattak AA, Saleem A, Javed $F$, Siddiqui $N$, Hussain $N$. Incidence of Typhoid Fever in Islamabad, Pakistan. Am-Euras J Toxicol Sci 20 I 5;7(4):220-3.

II. Sushila D, Rooma M, Priyanka S, Archana S, Rakesh L, Kabra SK, et al. Current antibiotic use in the treatment of enteric fever in children. Indian J Med Res 2019 Feb; 149(2): 263-9. DOI: 10.4103/ ijmr.IJMR_199_18.

12. Islam A, Butler T, Kabir I, Alam NH. Treatment of typhoid fever with ceftriaxone for 5 days or chloramphenicol for 14 days: a randomized clinical trial. Antimicrob Agents Chemother 1993;37(8): 1572-5. DOI: I0.1 |28/ aac.37.8.1572.

13. Dutta P, Rasaily R, Saha MR, Mitra U, Bhattacharya SK, Bhattacharya MK, et al. Ciprofloxacin for treatment of severe typhoid fever in children. Antimicrob Agents Chemother 1993;37(5): I|97-9. DOI: 10.1128/ aac.37.5.1197.

14. Aggarwal A, Ghosh A, Gomber S, Mitra M, Parikh AO. Efficacy and safety of azithromycin for uncomplicated typhoid fever: an open label non-comparative study. Indian Pediatr 201 I; 48(7):553-6. DOI: 10.1007/s I33 I2-0I I-0093-y.

I5. Saha SK, Talkukder SY, Islam M, Saha S. A highly ceftriaxone resistant salmonella typhi in Bangladesh. Peadiatr Infect Dis J 1999; (18):387. DOI: $10.1097 / 00006454$ 199904000-00018.
16. Capoor MR, Nair D, Hasan AS, Aggarwal P, Gupta B. Typhoid fever: narrowing therapeutic options in India. Southeast Asian J Trop Med Public Health 2006;37(6): I I 70-74.

17. Capoor MR, Nair D, Deb M, Aggarwal P. Enteric fever perspective in India: emergence of high-level ciprofloxacin resistance and rising MIC to cephalosporins. J Med Microbiol 2007; 56: I | 3 |-32.

18. Chinh TN, Parry CM, Ha HD, Ly NT, Thong MX, Wain J, et al. A Randomized Controlled Comparison of Azithromycin and Ofloxacin for Treatment of Multidrug-Resistant or Nalidixic Acid-Resistant Enteric Fever. Antimicrob Agents Chemother 2000; 44:1855-9. DOI: 10.1128/ aac.44.7.1855-1859.2000.

19. Rai S, Jain S, Prasad KN, Ghoshal U, Dhole TN. Rationale of azithromycin prescribing practices for enteric fever in India. Indian J Med Microbiol 2012;30(I):30-3. DOI: 10.4103/0255-0857.93017.

20. Capoor MR, Rawat D, Nair D, Hasan AS, Deb M, Aggarwal P, et al. In vitro activity of Azithromycin, newer quinolones and cephalosporins in ciprofloxacinresistant Salmonella causing enteric fever. J Med Microbiol 2007; 56(II):|490-4. DOI: 10.1099/ jmm.0.47353-0.

21. Gordillo ME, Singh KV, Murray BE. In vitro activity of azithromycin against bacterial enteric pathogens. Antimicrob Agents Chemother 1993;37(5): | 203-5. DOI: 10.1 |28/ aac.37.5. 1203.

22. Chandey M, Multani AS. A comparative study of efficacy and safety of Azithromycin and Ofloxacin in uncomplicated typhoid fever. J Clin Diagn Res 2012;6(I0): I736-9. DOI: I0.7860/JCDR/ 2012/4702.263I.

23. Jeeyani HN, Prajapati BS, Bloch A. Enteric fever in children - clinical profile, sensitivity patterns and response to antimicrobials. GCSMC JMed Sci 20 I 5;4( I):40-3.

24. Upadhyay R, Nadka MY, 
Muruganathan A, Tiwaskar M, Amarapurkar D, Banka NH, et al. API recommendations for the management of typhoid fever. J
Assoc Physicians India 2015; 63(II):77-96.

25. Mushtaq S, Bhat AA, Rather GN, Akhter R, Bhat I, Wani T. Clinical profile of enteric fever in tertiary care hospital of Kashmir. Int J Contemp Pediatr 2017;4(5): 17547. DOI: |0.|8203/2349-329|. ijcp20I73779.

\section{AUTHORS' CONTRIBUTIONS}

Following authors have made substantial contributions to the manuscript as under:

AL: Concept and study design, acquisition of data, drafting the manuscript, final approval of the version to be published.

MNC: Analysis and interpretation of data, drafting the manuscript, final approval of the version to be published.

AHR \& MA: Analysis and interpretation of data, critical review, final approval of the version to be published.

Authors agree to be accountable for all aspects of the work in ensuring that questions related to the accuracy or integrity of any part of the work are appropriately investigated and resolved.

\section{CONFLICT OF INTEREST}

Authors declared no conflict of interest GRANT SUPPORT AND FINANCIAL DISCLOSURE NIL

\section{DATA SHARING STATEMENT}

The data that support the findings of this study are available from the corresponding author upon reasonable request

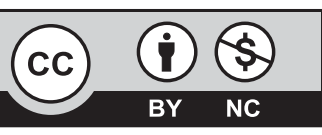

This is an Open Access article distributed under the terms of the Creative Commons Attribution-Non Commercial 2.0 Generic License.
KMUJ web address: www.kmuj.kmu.edu.pk

Email address: kmuj@kmu.edu.pk 